\title{
Gestão do trabalho e \\ da educação em saúde: recursos humanos em duas décadas do SUS
}

\author{
I ${ }^{1}$ Célia Regina Pierantoni, ${ }^{2}$ Thereza Christina Varella, ${ }^{3}$ Maria Ruth dos Santos, \\ ${ }^{4}$ Tania França, ${ }^{5}$ Ana Claudia Garcia I
}

Resumo: Este artigo discute os desafios contemporâneos que se apresentam no campo da gestão de recursos humanos em saúde no Brasil. Apresenta destaques da temática no continente americano, colocando em evidência o Brasil por suas características organizacionais nesse setor. Apresenta, ainda, os achados de uma pesquisa sobre a capacidade gestora de recursos humanos em Secretarias estaduais e municipais de Saúde de grandes centros urbanos e a capilaridade das políticas setorias de gestão do trabalho e da educação na saúde. A questão central diz respeito às mudanças ocorridas nessa área com a criação da Secretaria de Gestão do Trabalho e Educação na Saúde. Observa-se uma variação dos resultados, com índices de adesão mais significativos para as ações prioritárias da regulação do trabalho em relação aos programas estratégicos da educação em saúde. Tal fato configura, por um lado, um quadro em que os órgãos de recursos humanos têm o potencial para se constituírem, de fato, em espaços efetivos de gestão do trabalho do sistema de saúde; por outro, a necessidade de fortalecimento das competências para as políticas de educação. A partir da análise desses resultados, são apontados limites, acúmulos e possibilidades que se apresentam para apoiar as esferas subnacionais no Brasil, além de modelos que possam ser apropriados por países vizinhos de continente e da comunidade de língua portuguesa.

> Palavras-chave: recursos humanos em saúde, gestão do trabalho, gestão da educação.

\author{
${ }^{1}$ Médica; doutora em Saúde \\ Coletiva; professora adjunta \\ no Instituto de Medicina Social \\ da UERJ, coordenadora da \\ Estação de Trabalho IMS/UERJ \\ da Rede Observatório de \\ Recursos Humanos em Saúde. \\ Endereço eletrônico: \\ pieranto@infolink.com.br \\ ${ }^{2}$ Enfermeira; doutora em \\ Saúde Coletiva; professora \\ adjunta da Faculdade de \\ Enfermagem da UERJ; \\ pesquisadora na Estação de \\ Trabalho IMS/UERJ da Rede \\ Observatório de Recursos \\ Humanos em Saúde. \\ Endereço eletrônico: \\ varella@ims.uerj.br \\ ${ }^{3}$ Farmacêutica; doutora em \\ Saúde Coletiva, pesquisadora \\ visitante da Estação de \\ Trabalho IMS/UERJ da Rede \\ Observatório de Recursos \\ Humanos em Saúde. \\ Endereço eletrônico: \\ maria.ruth@ims.uerj.br \\ ${ }^{4}$ Estatística; doutora em Saúde \\ Coletiva; pesquisadora na \\ Estação de Trabalho IMS/UER \\ da Rede Observatório de \\ Recursos Humanos em Saúde. \\ Endereço eletrônico: \\ taniaf@ims.uerj.br \\ ${ }^{5}$ Socióloga; doutoranda em \\ Saúde Coletiva no Instituto de \\ Medicina Social da UERJ; \\ pesquisadora na Estação de \\ Trabalho IMS/UERJ da Rede \\ Observatório de Recursos \\ Humanos em Saúde. \\ Endereço eletrônico: \\ ana.claudia@ims.uerj.br
}


Todo paradigma teórico tem antolhos - enfoca apenas um conjunto restrito de fenômenos. No entanto, com a arrogância dos vitoriosos, os seguidores do paradigma liberal neoclássico afirmam que a sua visão é a única legítima.

Esber (2001)

A implementação do SUS induziu a expansão da rede pública de serviços de saúde e, conseqüentemente, a abertura de postos de trabalho, para uma gama de trabalhadores necessários à operacionalização da atenção à saúde, principalmente nas esferas subnacionais. Esse aumento do efetivo na esfera pública se mostra incompatível com as premissas de controle do déficit público face às exigências macroeconômicas, que ditam os rumos das políticas de privatização, flexibilização e desregulação.

Torna-se visível a centralidade da questão dos recursos humanos para a implementação do sistema. Por outra via, fica evidente a fragilidade gerencial de recursos humanos em saúde (RHS), pela incapacidade de compreender e articular uma bandeira política de orientação igualitarista e regulamentadora com os requisitos da administração flexível, focalizados na tendência neoliberal. Aos gestores de RHS impõem-se desafios gerenciais diversificados e cada vez mais complexificados pelas transformaçôes e exigências do trabalho contemporâneo. Exigências no campo da inserção de trabalhadores no serviço (que se apresentam sob formas variadas), da distribuição, da fixação, do desempenho e da qualificação, da motivação e accountability profissional, do resgate de padrões éticos, mas, sobretudo, da incorporação de qualificações gerenciais à área de RHS para lidar com todo esse processo em transformação.

Este artigo discute os desafios contemporâneos que se apresentam no campo da gestão de recursos humanos em saúde no Brasil. A questão central diz respeito às mudanças ocorridas nessa área com a criação da Secretaria de Gestão do Trabalho e Educação na Saúde (SGTES). Tal órgão, além de instituir as diretrizes nacionais da política de RH em saúde, vem adotando estratégias indutoras com investimentos técnicos, políticos e financeiros para a qualificação da gestão. Apresenta, ainda, os resultados de uma pesquisa sobre a capacidade gestora de RHS em Secretarias estaduais e municipais de Saúde de grandes centros urbanos 
e a capilaridade das políticas setorias de gestão do trabalho e da educação na saúde. A partir da análise desses resultados, são apontados limites, acúmulos e possibilidades que se apresentam para apoiar as esferas subnacionais no Brasil, além de modelos que possam ser apropriados por países vizinhos do continente e da comunidade de língua portuguesa.

\section{Destaques da gestão de recursos humanos no continente americano}

O processo de globalização revela a sua face real, bem distanciada da pretensa aproximação dos povos e de acesso mais igualitário às benesses do desenvolvimento científico e tecnológico (SANTOS, 2001). Tal processo, pelo contrário, acirra a assimetria entre os países, elevando os patamares de pobreza de um conjunto majoritário de nações que concentram dois terços da população mundial, cujas condições críticas de saúde são nodais para alcançar qualquer meta de desenvolvimento (PIERANTONI; VARELLA; FRANÇA, 2004). Corroborando este entendimento, Santos (2002) destaca a área da saúde como aquela na qual, possivelmente, a iniqüidade se revela como a mais chocante do mundo.

Estudos baseados em evidências apontam que a possibilidade de superação da dramática situação de saúde de uma parcela significativa da população está associada à disponibilidade de uma relação mínima de recursos humanos por número de habitantes. Estima-se que pelo menos 1,3 bilhão de pessoas esteja sem acesso aos cuidados médicos mais básicos, ou seja, abaixo do percentual recomendado pela Joint Learning Initiative (2004) de 2,5 trabalhadores de saúde por mil habitantes, limite mínimo necessário para atingir a cobertura de saúde adequada.

Neste sentido, considerando a força de trabalho no setor como a "medula" dos sistemas sanitários, a OMS dedicou o ano de 2006 e a década nesse ano iniciada aos trabalhadores da saúde, sendo também o tema do "Relatório Mundial da Saúde de 2006 - Trabalhando juntos para a saúde”. O relatório propõe a construção de um plano decenal, orientando que os países busquem formas de planejamento, qualificação e empregabilidade e fixação de médicos, enfermeiros e auxiliares.

A gestão da área de RH nos países da América Latina e Caribe passa também a ser alvo de investigação, na busca de processos e estruturas organizacionais que possam assumir os desafios que se colocam na atualidade. Estudo sobre o perfil das Unidades de Recursos Humanos dos Ministérios da Saúde das Américas e 
Caribe (ARROYO, 2007) aponta que, para o alcance das metas do Plano Decenal da OMS, há necessidade de se conhecer a capacidade operacional desses países na área de gestão de RHS. Tal necessidade se justifica na medida em que o desenvolvimento dos órgãos especializados dos Ministérios não é proporcional à relevância assumida pelo tema nos últimos anos. O estudo ressalta a existência de uma transição regional das unidades de $\mathrm{RH}$, uma vez que a maior parte dos países pesquisados encontra-se em situação de reestruturação progressiva, iniciada no final da década de 1990. Nesse contexto, Brasil e Canadá destacam-se pela relevância dada ao tema e a pertinência organizacional de suas unidades, ambos com unidades de RH no primeiro nível das estruturas de seus ministérios, sinalizando a importância dada à área nesses países.

Observa-se, então, que a gestão de RHS nos diferentes países apresenta-se de forma difusa e guarda relação com a especificidade da organização do sistema de saúde. Por exemplo, no Canadá, um governo provincial para melhorar os indicadores do Care Assistance Delivery (CAD) investiu cerca de 6,3 milhōes para aumentar o recrutamento, a retenção e a formação de enfermeiros na província. Os médicos de família não são empregados do governo, mas contratados sob a forma de prestação de serviço público. Há um incentivo à formação de médicos de família para atender às necessidades das províncias. Por outro lado, são enfrentados desafios para a boa gestão dos conhecimentos e práticas a serem desenvolvidas em hospitais.

A introdução de equipes interdisciplinares de saúde em hospitais canadenses é um fenômeno relativamente recente, e sua conexão com a gestão do conhecimento e agendas políticas dos governos e das administrações hospitalares levanta questôes importantes sobre a forma de organização do trabalho que favoreça o enfrentamento de um dos mais difíceis aspectos da gestão do conhecimento: saberes diversos, horizontalizados e democratizados. Interdisciplinaridade em saúde é uma abordagem centrada no doente, na qual todos os envolvidos, incluindo o paciente, têm contribuição nas decisões tomadas (KABENE et al., 2006).

No Brasil, até o ano de 2003, a área de recursos humanos encontrava-se a cargo de uma coordenação geral no terceiro escalão do Ministério da Saúde (MS). A partir desse ano, com a criação da SGTES, no conjunto de medidas para a reestruturação do ministério ocupando o primeiro escalão, é reafirmada a relevância da área de recursos humanos para o desenvolvimento da Política Nacional de Saúde.

A SGTES é criada com o desafio de buscar o equacionamento dos problemas 
existentes e de definir políticas no campo da gestão do trabalho e da educação para o efetivo desempenho do Sistema Único de Saúde (SUS) de forma articulada com as instâncias federativas gestoras do sistema. Mais ainda, de assumir, entre outros, papel estratégico nas diretrizes intersetoriais que envolvam o desenvolvimento de uma Política Nacional de Recursos Humanos em Saúde (PNRHS).

Comparado com os demais países da América Latina e Caribe, segundo estudo coordenado por Juan Arroyo (2007), o Brasil encontra-se numa situação privilegiada no que diz respeito à estruração da área de recursos humanos no nível federal. Além de estar entre os países que apontam o momento atual como o de melhor posicionamento da unidade de RH nos últimos dez anos, tal unidade possui um respaldo normativo de mais alto nível legislativo. Destaca-se também pelo grau de profissionalização dos trabalhadores no setor, contando com doutores e mestres no seu quadro de pessoal, além de diretores estáveis que ocupam o cargo há mais de dois anos e com, pelo menos, 20 anos de experiência na área.

Em relação à infraestrutura do órgão de $\mathrm{RH}$, o país apresenta-se entre aqueles com melhores indicadores. No entanto, o espaço físco ainda é apontado como insuficiente frente à quantidade de profissionais e o nível de importância das funções que realizam. Embora os recursos financeiros recebidos pelas estruturas de RH ainda sejam considerados limitados, a unidade de RH do Brasil está entre as que receberam um dos maiores montantes de recursos (acima de 3 milhôes de dólares) entre 2005 e 2007, ostentando importante aumento nos últimos três anos.

De fato, a estrutura brasileira de RHS sofre importantes tranformações nos últimos cinco anos, mas ainda apresenta fragilidade nas estratégias de gestão para responder às tranformações contemporâneas do trabalho na sociedade e lidar com a especificidade do trabalho no subsetor público de saúde.

\section{Gestão de recursos humanos nos anos recentes}

O mundo contemporâneo vem experimentando inovações nos processos de gestão, horizontalizando as funções de gerência, (re)nomeando e (res)significando a gerência de recursos humanos para a gestão de pessoas no sentido de "humanizar" a área e valorizar o capital humano e, ao mesmo tempo, buscar qualidade, produtividade e competitividade. Ou seja, desenvolver novos estilos gerenciais, visto que as formas tradicionais já não respondem às exigências de competitividade no mercado. Ao trabalhador são imputados novos atributos via ampliação de seus conhecimentos e 
busca pela polivalência funcional, para garantir espaços no mundo cada vez mais restrito de oportunidades de emprego.

Em que pesem os avanços sociais que trouxeram relações mais democráticas e pessoas com mais sentido de autonomia no trabalho, o emprego já não desempenha mais o papel de construir identidades sociais e de classe. Da mesma forma, as expectativas de carreira nas empresas ficam cada vez mais escassas (SORJ, 2000). A adoção de propostas para a progressão na carreira é de curta temporalidade, sujeita à vulnerabilidade de conjunturas políticas.

Por outra via, a classe trabalhadora perdeu a possibilidade de manutenção de identidade e de capacidade de organização e de ação coletiva. A pretensa mudança, longe de favorecer o trabalhador, vem subtraindo conquistas e multiplicando responsabilidades. $\mathrm{O}$ individual se sobrepõe ao coletivo. A carreira não é mais da empresa, mas do trabalhador, que traz para si o encargo de construir seus espaços de empregabilidade. Assim, embora as novas formas de produção não sejam ainda capazes de romper totalmente com os princípios da administração científica, no campo da saúde é possível observar a busca pela criação de espaços coletivos de gestão e a valorização da capacidade de expressão dos trabalhadores. Entretanto, ainda estamos perseguindo mecanismos mais eficazes que tanto contemplem as exigências de qualidade dos serviços, quanto os anseios de melhores condições de trabalho para os profissionais.

$\mathrm{Na}$ seqüência discutiremos, como já referido, os achados da pesquisa realizada sobre a capacidade gestora de RHS em Secretarias estaduais e municipais de Saúde de grandes centros urbanos, analisando a capilaridade das políticas setoriais de gestão do trabalho e da educação na saúde.

\section{Procedimentos metodológicos}

Trata-se de um estudo que conjugou métodos quantitativos e qualitativos e foi dirigido aos gestores de recursos humanos de Secretarias de Saúde das capitais, das secretarias estaduais, dos municípios com população superior $50 \mathrm{mil}$ habitantes, e com mais de 500 postos de trabalho público em saúde. Considerando esses critérios de inclusão, foram identificadas 388 estruturas como público-alvo. Na etapa de organização para execução do estudo, foram finalizados 337 cadastros de Secretarias de Saúde. Do universo cadastrado, a pesquisa foi concluída em 253 secretarias no ano de 2008. 
Os dados que informam esta discussão são resultantes da aplicação de um survey e da realização de grupos focais. O survey foi composto por 74 questões, divididas em cinco blocos: identificação, relacionamento com a SGTES, gestão do trabalho, gestão da educação e opinativas. Após sua elaboração, foi confeccionada uma máscara para resposta e processamento dos dados em meio informático. Para o processamento das respostas, utilizou-se o programa Sphinx, software específico para o tipo de pesquisa adotada que permite a tabulação e análise estatística direta dos dados coletados.

A partir da análise dos resultados, identificaram-se informações que mereciam, pela importante relação com o tema central, investigação mais acurada. Optou-se, então, por realizar grupos focais com os gestores/responsáveis de RH das Secretarias de Saúde dos estados e das capitais. Dessa forma, realizaram-se grupos focais com 31 representantes das secretarias, distribuídos conforme o quadro 1.

\section{Quadro 1 - SES e SMS participantes do grupo focal de acordo com grupo de realização e regiáo do país}

\begin{tabular}{|l|l|}
\hline $1^{2}$ Grupo & $\begin{array}{l}\text { 2 SES e } 1 \text { SMS da Região Sul e 2 } \\
\text { SES e } 3 \text { SMS do Sudeste }\end{array}$ \\
\hline $2^{2}$ Grupo & $\begin{array}{l}2 \text { SES e } 1 \text { SMS da Região Norte e 4 } \\
\text { SES e } 3 \text { SMS do Centro-Oeste }\end{array}$ \\
\hline $3^{2}$ Grupo: & 8 SES e 5 SMS da Região Nordeste. \\
\hline
\end{tabular}

Antes de iniciada essa etapa, solicitou-se aos participantes que respondessem a um "questionário aprofundado", com cinco questôes dissertativas. Essa estratégia foi adotada a fim de que fossem ampliadas as discussões de temas com capacidade de esclarecer e fortalecer pontos abordados na pesquisa. As questóes focalizaram a autonomia dos gestores, a localização do órgão de RH no organograma da SMS/ SES, vantagens e desafios para elaboração e implantação do PCCS, a utilização da informação para área, aspectos positivos e negativos dos Pólos de Educação Permanente em Saúde e uma avaliação das parcerias entre as SMS/SES e as instituições de ensino superior/escolas técnicas. 
Em seguida realizou-se o grupo focal, com a formulação de três perguntas a serem debatidas pelos participantes, enquanto eram anotadas e gravadas pelos pesquisadores. As informaçôes obtidas por escrito foram digitadas e os depoimentos literalmente transcritos. Na seqüência, sistematizaram-se as informações segundo a região, para subsidiar a análise do material resultante. As evidências que apóiam as interpretações realizadas podem ser verificadas a seguir, na apresentação de seus resultados.

Cabe ressaltar que, para analisar as tendências da gestão do trabalho e da educação no SUS neste artigo, foram selecionadas algumas diretrizes que tiveram peso mais decisivo na estruturação e organização dos órgãos de RH, tanto nas competências vinculadas à gestão do trabalho (Plano de Cargos, Carreiras e Salários - PCCS, Mesa de Negociação Permanente do SUS, Sistema de Informação, Programa de Estruturação e Qualificação da Gestão do Trabalho e da Educação no SUS - ProgeSUS), quanto nas da gestão da educação (Pólos de Educação Permanente em Saúde - PEPS e Programa Nacional de Reorientação da Formação Profissional em Saúde - Pró-Saúde).

\section{Analisando as tendências para a gestão do trabalho e da educação no SUS}

Como já referido, das 337 estruturas de $\mathrm{RH}$ que integravam o público-alvo da pesquisa, 253 gestores responderam o survey, incluindo todas as SES e as 23 SMS localizadas em capitais, como mostra a tabela 1 .

Tabela 1 - Universo e cobertura da pesquisa. Brasil, 2008

\begin{tabular}{c|c|c|c}
\hline \multirow{2}{*}{ Tipo } & \multirow{2}{*}{ Universo } & \multicolumn{2}{|c}{ Cobertura } \\
\cline { 3 - 4 } & & $\mathbf{N}$ & $\%$ \\
\hline Capitais & 26 & 23 & 88,5 \\
\hline Secretarias Estaduais & 27 & 27 & 100,0 \\
\hline Secretarias Municipais & 284 & 203 & 71,5 \\
\hline Total & $\mathbf{3 3 7}$ & $\mathbf{2 5 3}$ & $\mathbf{7 5 , 1}$ \\
\hline
\end{tabular}

Fonte: Pesquisa Gestão do Trabalho e da Educação em Saúde.

ObservaRH/IMS-UERJ. Brasil, 2008. 
A existência de órgão de $R H$ na estrutura da Secretaria de Saúde investigada foi observada em 76,3\% do universo respondente. Quanto à denominação do cargo do responsável pelo setor de $\mathrm{RH}$, verificou-se a existência de diferentes nomenclaturas para semelhantes cargos. Dessa forma, algumas denominações foram agrupadas como gestor de $\mathrm{RH}$, o que represento $44,3 \%$ do total.

Os resultados obtidos com o questionário aprofundado apontam que, nas SES e nas SMS das capitais, o órgão de RH está predominantemente no terceiro escalão hierárquico, fato só contrariado no conjunto representante da Região Nordeste, onde parcela expressiva refere inserção no segundo escalão da secretaria, o que em tese confere a estas estruturas uma maior aproximação do núcleo do poder.

Observam-se situações bem diversificadas: algumas em que os órgãos de RH seguem a modelagem da SGTES, inclusive na nomenclatura, e outras, onde as estruturas das secretarias foram recentemente alvo de reformas administrativas. Nestas, o órgão de recursos humanos passa a ser integrado a estruturas de logística ou de modernização administrativa, sendo responsável apenas pelas tradicionais atribuições de administração de pessoal, com completo distanciamento entre atividades de gestão e de educação.

Em relação à autonomia do gestor de $R H$, observou-se ambigüidade de posicionamentos. Esta se caracteriza tanto pelo entendimento do termo em seu caráter polissêmico, quanto pela capacidade dos gestores de avaliar sua posição e influência no poder setorial. $\mathrm{O}$ conjunto dos achados permite inferir que não houve avanço expressivo neste atributo e que a área de RH está mais caracterizada pelo cumprimento de atividades burocráticas do que como estratégica para tomada de decisão.

A questão central do estudo era investigar mudanças ocorridas na estrutura dos órgãos de RH decorrentes da criação da SGTES. A análise do survey mostrou que para $47,8 \%$ das secretarias investigadas, em especial as estaduais e as localizadas nas capitais, foi possível associar algum tipo de mudança induzida pelas políticas implementadas, conforme descrito na tabela 2 . 


\begin{tabular}{lcc}
\hline Mudanças no órgão de RH & Total & \multicolumn{1}{c}{$\%$} \\
\hline Sim & 121 & 47,8 \\
Não & 61 & 24,1 \\
Não sabe avaliar/não & 71 & 28,1 \\
resposta & $\mathbf{2 5 3}$ & $\mathbf{1 0 0 , 0}$ \\
\hline Total
\end{tabular}

Fonte: Pesquisa Gestão do Trabalho e da Educação em Saúde.

ObservaRH/IMS-UERJ. Brasil, 2008.

Considerando a diretriz da SGTES de que os órgãos gestores e executores de ações e serviços de saúde das esferas de governo elaborem e implantem Plano de Cargos, Carreiras e Salários (PCCS), percebe-se na tabela 3 que, neste conjunto, $47,8 \%$ responderam não contar com PCCS para seus trabalhadores e apenas $11,8 \%$ têm PCCS aprovados e implantados. Muito embora essa recomendação integre os documentos da área e ocupe lugar de destaque na agenda atual e na de discussões e deliberações dos principais fóruns realizados nas duas últimas décadas, ainda é elevado o contingente das secretarias que não articularam tal ferramenta. Para aqueles que afirmaram mudanças a partir da SGTES, apenas 21 estruturas possuem PCCS específicos para a saúde aprovados e implantados. 
Tabela 3: Plano de Cargos, Carreira e Salários (PCCS), segundo responsável pelo órgão de RH das Secretarias de Saúde das capitais, SES e SMS. Brasil, 2008.

\begin{tabular}{lrrrrr}
\hline \multicolumn{1}{c}{ PCCS } & Capitais & SES & SMS & Total & $\begin{array}{c}\text { Freqüência } \\
(\%)\end{array}$ \\
\hline Não possui PCCS & 6 & 8 & 107 & 121 & 47,8 \\
Sim, geral para todos os trabalhadores & 5 & 5 & 63 & 73 & 28,9 \\
Sim, específico da SMS/SES & 12 & 13 & 26 & 51 & 20,2 \\
Não sabe & 0 & 0 & 6 & 6 & 2,4 \\
Não-resposta & 0 & 1 & 1 & 2 & 0,8 \\
\hline Total & $\mathbf{2 3}$ & $\mathbf{2 7}$ & $\mathbf{2 0 3}$ & $\mathbf{2 5 3}$ & $\mathbf{1 0 0 , 0}$ \\
\hline
\end{tabular}

Fonte: Pesquisa Gestão do Trabalho e da Educação em Saúde.

ObservaRH/IMS-UERJ. Brasil, 2008.

Os achados decorrentes do questionário aprofundado apontam o reconhecimento pelos gestores de vantagens na adoção deste instrumento, tanto do ponto de vista da gerência, quanto da perspectiva dos trabalhadores. Destacam a especificidade da carreira na área da saúde como justificativa de um PCCS diferenciado, bem como o fato de ele se constituir como instrumento de agilidade para o planejamento e para a previsão orçamentária dos custos com pessoal. Além disso, consideram que, por ser um instrumento fruto de pactuação entre os diferentes segmentos, seu êxito é facilitado pela adesão das partes envolvidas.

Contudo, são pontuados inúmeros desafios que transitam por questōes de natureza legal, financeira, técnica e política, que constituem barreiras restritivas a sua viabilização. Estão elencados abaixo aqueles que julgamos mais relevantes no dimensionamento da tensão que envolve a questão:

[...] planos de carreira implicam em dispensa e nem sempre o planejamento financeiro considera tal premissa. (Gestor 1).

[...] a elaboração de um PCCS enseja a participação também dos representantes dos servidores, o que torna tal missão ainda espinhosa, pois as lideranças sindicais às vezes não possuem conhecimentos técnicos para a discussão [...] (Gestor 2). 
[...] há resistência, devido ao aumento da autonomia da área de gestão da saúde frente à gestão de pessoal da Prefeitura como um todo. (Gestor 4).

Percebe-se, tanto em termos de percentuais de secretarias com PCCS implantados e aprovados, quanto na narrativa dos gestores, que a utilização desta ferramenta ainda se apresenta com muitas barreiras e fragilidades, ainda que o mesmo seja apontado como instrumento facilitador da gestão. Tal fato pode estar relacionado à inexistência de modelos alternativos para a progressão dos trabalhadores e de carreiras flexíveis para o SUS.

Reveste-se, também, de similar magnitude a explícita política em favor do trabalho decente no SUS, o DesprecarizaSUS, Programa de Desprecarização do Trabalho no SUS, que visa à regularização da situação dos vínculos precários dos trabalhadores inseridos no sistema. Entretanto, no survey não foi observada a capilaridade desta política nas secretarias pesquisadas, tanto pelo desconhecimento deste programa $(32,4 \%)$, quanto pelo fato de que, dentre os que alegam conhecê-lo, dele não participam (40,1\%). Foi explicitado ainda por uma parcela reduzida dos respondentes que a secretaria não conta com trabalhadores desprotegidos em seu quadro.

Independentemente das diretrizes preconizadas pelo Programa Nacional de Desprecarização do SUS, os gestores de RH declararam empreender ações para resolução dos vínculos em situação precária, sendo a realização de concursos e processos seletivos públicos a ação mais citada. Foi visível nas intervenções, durante o grupo focal, a preocupação de gestores com mecanismos e metodologias que possam subsidiar o dimensionamento das necessidades de pessoal para a realização do concurso público. Tais metodologias para cálculo de efetivos não integram ainda a agenda do MS para a área.

No conjunto de diretrizes políticas da SGTES para a gestão do trabalho no SUS, destaca-se também a advocacia por utilização de mecanismos negociais para resolução de conflitos no setor público de saúde, consubstanciada pela recomendação de que sejam adotadas Mesas de Negociação Permanente do SUS nos demais níveis de governo. Por meio do survey, o estudo verificou que apenas $27,3 \%$ adotaram este mecanismo. Cabe ressaltar que quatro SES e duas SMS de capitais estão neste grupamento. 
A absorção desta política pelas demais esferas de governo vai demandar esforços adicionais do nível federal e maior escuta às Secretarias de Saúde para identificação de barreiras políticas e técnicas para a implantação e implementação de mecanismos mais participativos de negociação das tensões trabalhistas, considerando a característica de essencialidade da saúde no pleno exercício dos direitos sociais.

O Programa de Qualificação e Estruturação da Gestão do Trabalho e da Educação no SUS (ProgeSUS), segundo observado no survey, é conhecido por 89,0\% dos respondentes, com destaque para o segmento dos que afirmam mudanças por influência da SGTES (95,9\%). Ressalta-se a importante parcela deste último segmento, com projeto de adesão aprovado (77,6\%). Os dados revelam que 63\% dos gestores referem a existência de sistemas de informação no órgão de RH. Contudo, não creditam esta ocorrência ao componente de fortalecimento do uso de informação do ProgeSUS, tendo em conta que os projetos de adesão ao programa são de temporalidade recente.

O questionário aprofundado apresenta um cenário mais alvissareiro, em especial para estruturas do Sul e Sudeste, que revelaram a utilização de sistemas de informação específicos para a gestão de RH. Já as estruturas das regiōes Norte, Centro-Oeste e Nordeste denunciam limitaçôes de acesso e uso da informação, seja pela centralização em órgãos da administração municipal, seja pela desestrutura local. $O$ fato é que, neste conjunto, a informação está fragmentada, insuficiente e refém de métodos artesanais de coleta e de processamento. O esforço do MS, fomentando e disponibilizando sistemas de informações gerencias para RH, é plenamente justificável e necessário para a profissionalização e qualificação da área.

Se a gestão do trabalho ainda merece a mobilização de investimentos para sua qualificação, a gestão da educação mostra uma diáspora nas atribuições da gestão de RH. Os resultados dos estudos realizados anteriormente (ObservaRH/IMS/ UERJ, 2004) apontam as atividades de "capacitação" no rol daquelas que os gestores de $\mathrm{RH}$ referiam deter maior autonomia para a realização. Vale lembrar a conjuntura da época, em que os pólos de educação permanente, propostos pela recentemente institucionalizada SGTES, ainda estavam em processo gestacional. Mais ainda, com a implantação dos Pólos de Educação Permanente em Saúde (PEPS), o poder decisório para eleição de prioridades, bem como de operacionalização dos processos educativos, deslocam-se da gestão de RH para arenas de negociação, onde um conjunto de atores passa a decidir sobre tais processos. 
De acordo com informações obtidas no survey, $46,2 \%$ das secretarias estavam referenciadas a algum pólo e $22,9 \%$ não souberam responder à questão. Ao abordamos esse tema no questionário aprofundado, verificamos a diminuta relevância da área no rol de atuação do gestor, tanto pela alegação de que vários participantes não conhecem bem essa política, quanto por sua baixa atuação nestas instâncias. Observamos também a incapacidade dos gestores de avaliar as mudanças presumidas pela Portaria GM/MS no 1.996/2007, pelo exíguo tempo de se reverter em mudanças para a área.

No que concerne ao Programa Nacional de Reorientação da Formação Profissional em Saúde (PRÓ-SAÚDE), cujo objetivo central é a integração ensinoserviço, visando à reorientação da formação profissional, observa-se, pelos dados do survey, que essa estratégia não é conhecida por $60,0 \%$ dos respondentes. Em síntese, era esperado que, no segmento que referiu mudanças a partir da criação da SGTES ( $\mathrm{n}=121$ ), o conjunto das estratégias analisadas tivesse peso mais decisivo em relação à implementação das iniciativas, o que acabou por se confirmar. No entanto, pode-se perceber que mesmo neste grupamento a incorporação das políticas emanadas pelo MS ainda é incipiente, como pode ser observado pelo reduzido número de secretarias com: PCCS específico aprovado no campo da área da gestão e integralmente implantado (21 estruturas); Mesas de Negociação do Trabalho para a Saúde (41 estruturas); adoção de instrumentos do DesprecarizaSUS (40 estruturas); adesão ao ProgeSUS (90 estruturas) e existência de sistema de informação para recursos humanos (83 estruturas).

Observa-se, portanto, que o conjunto de incentivos e de estratégias de indução e as orientações para as políticas pelo gestor federal são elementos fundamentais para a incorporação gradual das funções de gestão pelos entes federados, considerando o recente processo de descentralização e, mais ainda, de organização da área de gestão do trabalho no SUS.

Qualquer discussão que se faça em relação à gestão de RH terá que levar em consideração que a organização do SUS trouxe, no seu processo, a experiência descentralizadora no setor público de saúde, experiência esta carreada por diversos movimentos de mesma natureza, que se tornaram bandeira política na década de 1980, como princípio ordenador de reformas do setor público, ostentadas pelo apelo ao fortalecimento da democracia (MELO, 1996). Havia também, de forma quase consensual, a crença de que a descentralização aumentaria a eficiência na 
alocação dos recursos pelo sistema de governo. Assim, passados 20 anos de municipalização da saúde, ainda é voz corrente o questionamento sobre a qualidade da capacidade gestora neste ente federado. Isso porque o processo de descentralização não acarreta automaticamente a superação das dificuldades de gerência nestas instâncias de poder.

É neste contexto que se tem buscado analisar um recorte da gestão da saúde que, historicamente, herda um legado de descaso e invisibilidade: a gestão de recursos humanos. $\mathrm{O}$ aumento da visibilidade deste espaço de gestão tem como um dos marcos, no cenário brasileiro, a institucionalização, no âmbito do Ministério da Saúde, da Secretaria de Gestão do Trabalho e da Educação na Saúde que, além de reconfigurar esta área na política nacional, traz consigo acúmulo de poder para este campo de ação.

Entretanto, o MS tem que demonstrar não somente o poder de induzir políticas nos estados e municípios brasileiros, mas capacidade semelhante de acompanhamento, avaliação da implementação dessas políticas e dos instrumentos utilizados pelos gestores para operacionalizá-las. Assim, as análises apresentadas apontam para a necessidade do constante monitoramento e avaliação da operacionalização pelas instâncias federativas das políticas de gestão do trabalho e da educação em saúde para dar conta das especificidades da área e das tendências de mudanças nessas realidades administrativas, contribuindo para o aclaramento da estratégia de condução nacional das políticas do MS/SGTES.

\section{Considerações finais}

As Secretarias municipais e estaduais de Saúde e seus respectivos órgãos de recursos humanos são estruturas dos governos subnacionais que vêm nas duas últimas décadas experimentando redesenhos de seus mecanismos operacionais para viabilizar a constituição de um Sistema Único de Saúde e um modelo de prestação de serviços de saúde no país.

Numa perspectiva histórica, a Constituição Federal de 1988 estabeleceu a regra de que esse sistema deveria ser universal, hierarquizado, público e com comando único em cada esfera de governo, com transferência de atribuições de gestão do governo federal aos governos locais - estados e municípios. No entanto, essas modificações do formato centralizado de gestão para um padrão descentralizado e com capacidade técnica em termos físicos, organizacionais e 
de recursos humanos requerem um longo processo, sendo no caso da saúde, relativamente recente e ainda em curso.

Ao longo da década de 90, inicia-se a normatização e institucionalização do processo de descentralização, com aprofundamento da municipalização, o que determinou profundas mudanças na estrutura das relações de trabalho e a responsabilização dos municípios pela contratação e gerência de profissionais para dar conta dos múltiplos objetivos e metas do projeto de reforma setorial. Dados do IBGE informam que, na década de 1980, a esfera municipal respondia por cerca de $16,0 \%$ dos empregos públicos de saúde e, em 2005, por 68,8\%. Ainda segundo informações do Conasems, de 1998 a 2005, assistimos, no Brasil, a uma vertiginosa subida de empregos na área de saúde, passando de 1,5 milhões para 2,5 milhões, sendo um milhão de empregos somente nos municípios brasileiros, que ficam com menos de $17 \%$ das receitas tributárias totais.

Diversas podem ser as razões e outras variáveis podem interferir na estruturação e institucionalização das condições organizacionais para o exercício, em nível local, de determinadas tarefas de gestão de recursos humanos. No entanto, a trajetória recente do processo de descentralização da política pública de saúde certamente contribui para explicar a alta incidência $(76,3 \%)$ de órgãos de $\mathrm{RH}$ presentes nas estruturas das Secretarias de Saúde e, por outro lado, em 52,2\% dos pesquisados, de que as transformações já estivessem em curso independentemente das estratégias e políticas que vêm sendo propostas pelo MS/SGTES.

Em geral, os órgãos de recursos humanos das SES e SMS, em especial as das capitais, vêm colocando em prática instrumentos da agenda da política de gestão do trabalho e da educação em saúde, ainda que ocorram variações expressivas na amplitude e na extensão dessa implementação. Neste quadro fica clara a colaboração que as SES podem dispensar no cumprimento do seu papel de articulação e cooperação técnica, no que se refere à estruturação de efetiva política de gestão do trabalho e da educação na indução da capacidade regulatória e de planejamento da função recursos humanos nos municípios.

Outra evidência encontrada na pesquisa diz respeito às variações no alcance das funções de gestão no desempenho das ações do componente da educação e do trabalho. Observa-se uma variação dos resultados, com índices de adesão mais significativos para as ações prioritárias da regulação do trabalho em relação aos programas estratégicos da educação em saúde. Tal fato configura, por um lado, um 
quadro em que os órgãos de recursos humanos têm o potencial para se constituírem, de fato, em espaços efetivos de gestão do trabalho do sistema de saúde; por outro, a necessidade de fortalecimento das competências para as políticas de educação.

Para o desenvolvimento dos projetos da educação, é necessário haver articulação e aproximação da estrutura de gestão de recursos humanos do SUS com as instituições formadoras para o compartilhamento, responsabilidade na condução, acompanhamento e avaliação dos projetos de formação, qualificação e produção de pesquisas e estudos, fazendo valer o mandato constitucional que consagra essa parceria. As políticas, até então definidas, possuem caráter de externalidade, ou seja, muito mais voltadas para indução de reconversão profissional pelo setor educacional. Assim, observa-se ainda a necessidade de políticas indutoras que promovam o fortalecimento das ações de gestão da educação no interior das estruturas de RH do SUS.

Não há dúvida quanto à interferência da variável autonomia do respectivo órgão de recursos humanos na institucionalização da sua capacidade técnica, financeira, administrativa e organizacional, para garantir que as funçôes de gestão estejam sendo desempenhadas pela unidade de governo. Em que pesem todos os demais avanços alcançados, a autonomia na gestão de recursos orçamentários e financeiros e na definição de contratação de pessoal ainda se apresenta incipiente e com debilidades que comprometem a capacidade gestora da área.

Ainda assim, o movimento observado no campo da gestão de recursos humanos no SUS, recentemente alçado a uma posição estratégica de gestão do trabalho e da educação, vem tomando contornos mais visíveis nas políticas da saúde, ainda que se possam identificar avanços e retrocessos. As ações a serem desenvolvidas nesta área estão contempladas no pacto de gestão, responsabilizando estados e municípios no cumprimento das diretrizes emanadas pelo MS, com autonomia para suprir as necessidades do sistema local. Além disso, o recente Programa Mais Saúde ou o Programa de Aceleração do Crescimento da saúde, lançado em 2008 pelo governo federal, prioriza as ações de fortalecimento da gestão, ampliação e qualificação da força de trabalho em saúde para atender à política de saúde e às necessidades do SUS.

Neste sentido, considerando o tempo decorrido na organização do sistema de saúde de forma descentralizada e a tímida capacidade alocativa de investimentos na área, observa-se um redesenho do campo com potencialidades para romper o insulamento político e ocupar papel estratégico no processo decisório da gestão da 
saúde. A confirmação desta tendência requer o fortalecimento de mecanismos de accountability para a área, bem como a implementação de políticas indutoras de estruturação e qualificação da gestão.

Os mecanismos de gestão no campo de RHS ainda são processos em construção, que polarizam questôes conflitantes e polêmicas. Constituem desafios ainda em construção e suscitam uma série de reflexões sobre os modelos gerenciais para recursos humanos no setor saúde. De acordo com Novick (2006), há uma agenda inconclusa de reconstrução de capacidades que transitam por desafios decorrentes da globalização como a migração e a debilidade das autoridades sanitárias e, especificamente, a fragilidade da gestão de RH nos diferentes níveis de atenção, demandando maior articulação sistêmica.

No Brasil, mesmo considerando os avanços decorridos nos últimos anos, os desafios não são de menor intensidade. Destacaremos alguns que consideramos urgentes para a agenda dos gestores da área: será viável estabelecer padrões únicos de carreira para o SUS, em um país federativo, com imensas diversidades e ampliada a alteridade dos profissionais? Os processos de educação permanente oferecidos pelo SUS serão atrativos para profissões com maior competitividade no mercado? Como estabelecer a desprecarização do trabalho sem discutir com mais profundidade a aplicação na saúde da lei de responsabilidade fiscal e uma reforma tributária que lhe ofereça base de sustentação material? As fundações estatais de direito privado poderão oferecer vantagens comparativas aos modelos até hoje adotados?

\section{Referências}

ARROYO, J. Resultados Preliminares del Estudio del Perfil de lãs Unidades de Recursos Humanos de los Ministerios de Salud de América Latina y el Caribe. 2007.

ESBER, F. Prefácio. In: TAUILE, J.R. Para (re)construiro Brasil contemporaneo: trabalho, tecnologia e acumulação. Rio de Janeiro: Contraponto, 2001. p. 8.

JOINT LEARNING INICIATIVE. Human Resources for Health: overcoming the crisis (studies in global equity). Cambridge, Massachusets: Harvard University, 2004.

KABENE S.M. et al. The importance of human resources management in health care: a global context. 2006. Disponível em: http://www.human-resources-health.com/content/4/1/20. Acesso em: 10 set. 2008.

MELO M.A. Crise Federativa, guerra fiscal e "Hobbesianismo municipal": efeitos perversos da descentralização? São Paulo em Perspectiva, v. 10, n. 3, p. 1-14, 1996. 
NOVICK M. Desafios de la Gestión de los Recursos Humanos em Salud - 2005-2015. 2006.

ObservaRH/IMS/UERJ. Capacidade gestora de recursos humanos em instâncias locais de saúde em municípios com população superior a 100 mil habitantes. Rio de Janeiro: IMS/UERJ, 2004.

PIERANTONI C.; VARELLA T.; FRANÇA T. Recursos humanos e gestão do trabalho em saúde: da teoria para a prática. In: BARROS, A.F.R. et al (org.). Observatório de recursos humanos em saúde no Brasil: estudos e análises, v. 2. Brasília: Ministério da Saúde, 2004. p. 51-70.

SANTOS, B. S. Os processos da globalização. 2002. Disponível em: http://www.eurozine.com/ articles/2002-08-22-santos-pt.html. Acesso em 10 set. 2008.

SANTOS M. Por uma outra globalização: do pensamento único à consciência universal. Rio de Janeiro: Record, 2001.

SORJ, B. Sociologia e trabalho: mutações, encontros e desencontros. Revista Brasileira de Ciências Sociais, v. 15, n. 43, p. 25-34, 2000. 


\section{Health care work and education}

management in the SUS: human resources in 20 years of the Unified Health System

This paper discusses the current challenges in health human resources management in Brazil. It presents highlights of the theme in America, especially Brazil, due to its organizational characteristics. It also presents the findings of a research on the managerial ability of human resources in municipal and state Health Secretaries in large urban centers and the capillarity of sectorial work relations and education in health. The central issue concerns changes in this area, after the creation of the Secretary for Work and Education Management in Health. The results vary, with more significant adhesion indexes for prior actions in work regulation in health education strategic programs. This facts means, on one hand, that human resources are able to really become real spaces of work management in the health system; on the other hand, the need to strengthen competences for education policies. Analyzing these results, we point out limits, backlogs and possibilities to support the sub-national spheres in Brazil, besides models that can be adopted by Portuguese-speaking and Latin-American countries.

> Key words: health human resources; work management; education management. 